Revista Temas Socio Jurídicos

Vol. 38 No 77 Julio - Diciembre de 2019

ISSN: 0120-8578

ISSN electrónico: 2590-8901

\title{
DETENCIÓN ILEGAL Y LIBERTAD PERSONAL EN SUJETOS DE ESPECIAL PROTECCIÓN CONSTITUCIONAL EN COLOMBIA
}

\author{
Lorna Xiomara Palacios García ${ }^{1 *}$ \\ Recibido: Mayo 22 de 2019 \\ Aprobado: Agosto 21 de 2019
}

\begin{abstract}
RESUMEN:
En este artículo se explora la detención ilegal de sujetos con especial protección constitucional, en específico, de menores de edad, tanto en el ámbito interno del territorio colombiano como en el internacional. En esta investigación se comparan los ordenamientos jurídicos internacionales, a la vez que se contrastan las legislaciones en Panamá, Ecuador, Chile, Perú y Colombia. El propósito principal es enlazar las inferencias fundamentales que proporciona la información obtenida de los estudios en el territorio colombiano con la de los demás países, teniendo en cuenta el impacto de factores como organismos internacionales y otros potenciales actores doctrinales. El método acá expuesto ofrece un enfoque diferencial; está sujeto a diversidad de perspectivas que permiten entender si las herramientas de defensa, los medios procesales y los precedentes se ajustan a unos parámetros claros frente a la detención ilegal, distinguiendo además que cada noción es completamente disímil. En últimas permite identificar el origen de la detención ilegal; las autoridades en quienes recae la
\end{abstract}

Citar este trabajo como: Palacios, L. (2019). Detención ilegal y libertad personal en sujetos de especial protección constitucional en Colombia. En: Temas Socio-Jurídicos, 38(77), pp. 116-148. DOI: https://doi.org/10.29375/01208578.3733

$1 *$ Detención ilegal en sujetos de especial protección constitucional en Colombia; investigación en curso, línea de Investigación: Derecho y Sociedad, Grupo GEIS, Programa de Derecho, Fundación Universitaria del Área Andina, Seccional Pereira. Estudiante de X semestre del Programa de Derecho. ORCID: https://orcid.org/0000-0002-3687-8099. Correo electrónico: lpalacios14@estudiantes.areandina.edu.co. 
responsabilidad y la manera de neutralizar este crimen además de determinar si en el marco normativo del estado colombiano se acogen los derechos establecidos en la Comisión Interamericana de Derechos Humanos.

Palabras clave: Derechos; Derechos Humanos; detención ilegal; menores; protección constitucional.

\title{
ILLEGAL DETENTION AND PERSONAL FREEDOM IN SUBJECTS OF SPECIAL CONSTITUTIONAL PRO- TECTION IN COLOMBIA
}

\begin{abstract}
:
This article explores the illegal detention of subjects with special constitutional protection, specifically, minors, both within the internal scope of the Colombian territory, as well as abroad. This investigation compares international legal orders while contrasting legislations in Panama, Ecuador, Chile, Peru and Colombia. The main purpose is to connect the fundamental inferences provided by the information obtained from the studies within Colombian territory with that of other countries, considering the impact of factors such as international organizations and other potential doctrinal actors. The method expounded herein offers a differential focus; it is subject to a plethora of perspectives that help understand whether the defense tools, procedural means and precedents adjust to clear parameters regarding illegal detention, moreover signaling that each notion is completely dissimilar. Ultimately, it helps identify the origin of illegal detention; the responsible authorities and the way to neutralize this crime, in addition to determine if the regulatory framework of the Colombian state abides by the rights established in the Inter-American Commission on Human Rights.
\end{abstract}

Keywords: Rights; Human Rights; illegal detention; minors, constitutional protection.

\section{DETENÇÃO ILEGAL E LIBERDADE PESSOAL EM IN- DIVÍDUOS DE PROTEÇÃO CONSTITUCIONAL ESPE- CIAL NAA COLÔMBIA}

\section{RESUMO:}

Este artigo explora a detenção ilegal de indivíduos com proteção constitucional especial, especificamente de menores, tanto no território colombiano quanto internacionalmente. Nesta pesquisa são comparados sistemas 
jurídicos internacionais, contrastando as legislações do Panamá, Equador, Chile, Peru e Colômbia. O principal objetivo é vincular as inferências fundamentais fornecidas pelas informações obtidas nos estudos no território colombiano com as dos outros países, levando em consideração o impacto de fatores como organizações internacionais e outros possíveis atores doutrinários. O método aqui apresentado oferece uma abordagem diferencial. Ela está sujeita a uma diversidade de perspectivas que nos permitem entender se as ferramentas de defesa, os meios processuais e os precedentes estão em conformidade com parâmetros claros em relação à detenção ilegal, distinguindo, ainda mais, que cada noção é completamente diferente. Finalmente, possibilita identificar a origem da detenção ilegal, as autoridades nas quais recai a responsabilidade e a maneira de neutralizar esse crime, além de determinar se na normatividade do estado colombiano são acolhidos os direitos estabelecidos na Comissão Interamericana de Direitos Humanos.

Palavras-chave: Direitos; Direitos Humanos; detenção ilegal; menores; proteção constitucional.

\section{INTRODUCCIÓN}

El presente trabajo pretende resolver los diferentes objetivos planteados dentro del marco de detención ilegal y sus aspectos normativos tanto nacional (Colombia) como internacionalmente. Para ello es importante comenzar con la conceptualización general de esta figura; es decir, su aspecto doctrinal. Todo esto con el propósito de partir de lo general a lo específico y así lograr una visión integral. En este sentido se entenderá a los menores de edad como sujetos con especial protección constitucional de la detención ilegal en Colombia.

Teniendo en cuenta el tema, resulta esencial vincular la libertad personal, entendida como el bien jurídico que se transgrede al momento de presentarse una detención ilegal. Este derecho se desarrolla además en el plano internacional, otorgándosele reconocimiento fundamental.

Los antecedentes son escasos en este tema, así como las investigaciones y demás referentes teóricos que sustenten al sujeto de especial protección constitucional, lo que posibilita un momento comparativo con las legislaciones de otros países, puesto que dada la escasa indagación del tema, se pueden realizar propuestas inéditas. No obstante, no se deben olvidar los diferentes organismos internacionales encargados de regular las infracciones de Derechos Humanos en los Estados Partes. Así las cosas, se busca relacionar las corporaciones internacionales que funcionan como soporte jurídico en el ordenamiento interno del País en relación, puesto que son una pieza clave en el proyecto de investigación. Entre las corporaciones referidas están: la Comisión Interamericana de Derechos Humanos, la Convención Americana Sobre Derechos Humanos y similares que 
tipifican, por un lado, la libertad personal, y, por el otro, las detenciones ilegales (o aspectos similares).

El objetivo general es analizar los distintos preceptos del ordenamiento jurídico interno y la medida de aplicación, así como el derecho comparado en países como Panamá, Ecuador, Perú y Uruguay. Por esto resulta esencial ampliar el tema desde una perspectiva internacional. Con relación a las disposiciones internacionales sobre la libertad personal, se indagó el carácter fundamental de los derechos que se trasgreden con la detención ilegal, resaltando la dicotomía de los términos detención, aprehensión y arresto en el marco jurídico colombiano e identificando los presupuestos procesales que decretan las medidas privativas de libertad con relación a la Convención Americana sobre Derechos Humanos (art.7).

Un aspecto importante por abarcar es el de los precedentes jurisprudenciales o la ausencia de estos, puesto que es esencial traer a colación dicha información que permite vislumbrar la fuerza constitucional del tema que existe en el estado colombiano.

Por otro lado, la metodología empleada en este proyecto hace parte del tipo cualitativo, obedeciendo a una de las finalidades que plantea el presente trabajo y que encuentra soporte en las teorías asociadas.

Por último, esta investigación pretende aclarar jurídicamente, doctrinalmente y metodológicamente a los directos afectados sobre las acciones $\mathrm{u}$ omisiones en que incurren diferentes entes al vulnerar el derecho fundamental de la libertad personal al incurrir en detenciones ilegales. Para hacer tal aclaración, se recurre a la siguiente pregunta:

¿Qué derechos consagrados en la Convención Interamericana de Derechos Humanos (CIDH) en materia de libertad personal de menores se han implementado en el marco legal colombiano?

\section{MARCO METODOLÓGICO}

La presente investigación se desarrolló conforme a un enfoque cualitativo de preceptos legales y constitucionales en Colombia. Resulta relevante vincular las acciones que toma el Estado ante una detención ilegal en sujetos de especial protección constitucional, en específico, los menores de edad.

La investigación tuvo un desarrollo de tipo teórico-descriptivo: con base en fuentes documentales se estudiaron los componentes de las legislaciones de varios países como la jurisprudencia y la doctrina con respecto a las medidas de privación de libertad de los menores infractores. Se realizó un marco comparativo entre los países Panamá, Ecuador, Perú y Uruguay. La investigación se enfocó en analizar cómo es y cómo se manifiesta ese fenómeno y sus elementos estudiando sus propiedades en libros, investigaciones, artículos científicos, notas periodísticas y plataformas (tanto 
normativas como jurisprudenciales), siendo estos aspectos inherentes a la investigación teórica.

\section{LA LIBERTAD PERSONAL E INDIVIDUAL}

Una de las medidas cautelares personales que proporciona el Estado colombiano para restringir la libertad de los ciudadanos es la detención. Ajustada a los parámetros legales para su ejecución, funciona como una excepción legítima del derecho fundamental de la libertad individual, y permite entonces, el descubrimiento de la verdad de los actos ilícitos cometidos y la aplicación de la ley sustantiva. Sin embargo, el sustento legítimo de la Detención Ilegal se torna de forma irregular de acuerdo con el elemento de causalidad que se ejecuta de esta manera: El incumplimiento de los requisitos de ley que ocasiona la comisión de un delito grave, en términos de violación de los Derechos Humanos y disposiciones legales.

Antes de abordar el objeto de estudio es importante referenciar un elemento trascendente y de gran afectación: los derechos fundamentales y, en particular, el derecho a la libertad individual como principio básico.

La libertad individual es un derecho fundamental de carácter subjetivo y valor esencial que comprende un conglomerado de libertades consagradas en las normas constitucionales y pactos internacionales sobre Derechos Humanos. En este ámbito encontramos la libertad personal que traduce "libertad física o ambulatoria" y se reconoce claramente: el derecho de no tener limitaciones. En caso contrario, solo se dará en circunstancias excepcionales, pues una de sus garantías al titular es no verse irracionalmente privado del derecho referido. Es en este contexto en donde toma poder la acción de detención ilegal o arbitraria.

[la] libertad personal comprende la posibilidad y el ejercicio positivo de todas las acciones dirigidas a desarrollar las aptitudes y elecciones individuales que no pugnen con los derechos de los demás ni entrañen abuso de los propios, como la proscripción de todo acto de coerción física o moral que interfiera o suprima la autonomía de la persona juzgándola, sustituyéndola, oprimiéndola o reduciéndola indebidamente (Sentencia T-276/16).

Es importante resaltar su sustento constitucional, pues desde el preámbulo de la Constitución Política de Colombia de 1991 se define este derecho como uno de los bienes que debe asegurar el Estado. Los artículos 2 y 28 mencionan la carta política que debe proteger dichos derechos fundamentales a cargo de las autoridades competentes y, taxativamente, menciona este precepto constitucional como la libertad que toda persona goza además de las garantías pertinentes para su legítimo ejercicio. Así mismo, rechaza el abuso del poder en cuanto a las medidas de detención u otras. 


\section{BREVE RECUENTO HISTÓRICO}

El derecho de menores surgió aproximadamente en el siglo XX. La figura que se regulaba para ese entonces era la sustracción de menores infractores. Entre tanto, se presentaban dos modelos de reacción frente a la delincuencia que se debían salvaguardar para que no se originara una ilegalidad o irregularidad. El primero se denominaba "modelo tutelar o de protección", el cual estuvo vigente hasta los inicios de las jurisdicciones especializadas en menores. En este modelo se catalogaban como sujetos en formación que se tenían que separar de su ambiente social para realizar la "curación" en un centro específico. El segundo es el "modelo jurídico-garantista", que cobró vigencia en el año 1989 con la Convención Sobre Derechos del Niño. Desde allí se consolidan diferentes legislaciones tanto internamente en Colombia como en otros países.

Los antecedentes de la detención ilegal en menores o adolescentes son muy escasos, puesto que sus disposiciones normativas eran muy abstractas. Sin embargo, a continuación, se sintetiza el marco legal de algunos países, con el objetivo de ofrecer un panorama de esta figura en la antigüedad.

\section{a. Francia}

El derecho francés es uno de los primeros sistemas legislativos de que se tiene referencia en el tema de la responsabilidad penal con respecto a menores. Sin embargo, relatan doctrinantes que fue una de las legislaciones más represivas por los tratos dirigidos a los menores irresponsables, Blanco (s.f.) afirma. "Una ordenanza de 1268 consideraba con irresponsabilidad absoluta a los niños hasta los diez años, de ahí a los catorce recibirían amonestaciones o golpes, y a partir de los quince quedaban sujetos a las mismas penas que los adultos" (p.88).

Esto clara evidencia del trato represivo hacia los menores o infantes. De igual modo, no se contaba con una legislación plenamente garantista de los Derechos Fundamentales del Niño, ni tampoco su pleno desarrollo de los principios rectores en Derecho, como Dignidad humana, Debido proceso y similares.

\section{b. Inglaterra}

El derecho anglosajón aplicaba un régimen rígido en cuanto a la penalidad de menores, que iba desde su detención hasta la pena de muerte. En los siglos XIII en adelante se permitió una serie de reformas que reducían la pena de muerte y la condena en ciertas situaciones. Se refleja que, desde tiempos antiguos, la detención ilegal en el Derecho inglés no tuvo ningún tipo de amparo con respecto a los menores de edad.

Entre los años 1847 y 1908 nacen las Cortes Juveniles y con ellas una serie de prevenciones que servían para neutralizar la comisión de delitos en menores. Por lo tanto, se evidencia la función como Estado garantista, 
tanto en condiciones a los infractores como en las condiciones procesales y sustanciales.

\section{c. Chile}

La legislación en este país hasta el año 1876 no contaba con una regulación especial, puesto que la ley de menores comenzó a regir años más tarde. Con respecto a una conducta ilícita de un menor se aplicaba una ley general que regulaba a los adultos y a los menores por igual. Esta ley no comportaba los derechos fundamentales del menor ni salvaguardaba sus intereses.

A sus inicios se identificó el factor de discernimiento a partir de los nueve años, situación que permitía abusos y coerción.

En dicho periodo, que comienza con la dictación del Código Penal en 1876 y se extiende hasta la dictación de la primera Ley de Menores 4.447 de 1927, los menores de edad a partir de los dieciséis años son responsables penalmente por contar con discernimiento, mientras que entre los diez y los dieciséis años se le presume legalmente sin él, quedando al juez determinar lo contrario. Bajo este sistema los menores de diez años eran inimputables, y bajo los siete años incapaces de cometer delitos o cuasidelitos civiles, aplicando las normas del Código Civil. (Durán, 2010, p.18)

El Código Penal, en Chile se tipifica en el año 1890 que comenzó a regular esta materia, sin ninguna modificación de tipo fundamental respecto de menores, sólo hasta el año 1927 los menores disponen de regulaciones específicas y más protectoras.

De acuerdo a lo anterior, la detención ilegal en menores es un fenómeno muy antiguo y era común su ejecución y acciones represivas. Es solo hasta finales del siglo XIX que comienza la discusión de cómo proceder con los menores infractores, el reconocimiento de discernimiento y el peso de responsabilidad, de acuerdo a la edad del menor. Contrario a su regulación, que es técnicamente nueva y abstracta en algunos países, la normalización de pensar en un trato apropiado para los menores se da en el siglo XX. No obstante, por ser tan implícito el fenómeno, no termina de excluirse del tema penal.

\section{DETENCIÓN ILEGAL EN COLOMBIA}

La doctrina no ha establecido una noción consolidada acerca de la detención ilegal. Por lo tanto, la jurisprudencia y la ley de igual manera no han brindado un concepto con respecto a la misma; sin embargo, los organismos nacionales e internacionales se han pronunciado acerca de principios y acciones para la protección de algunos derechos que se vulneran con la detención ilegal. 
La detención que supone la privación de la libertad personal contempla el alcance de la noción conceptual de ilegal en el sentido de un delito en el que incurren funcionarios, órganos judiciales y jueces en el momento que realizan el proceso de aprehensión a una persona que no ha incurrido en algún delito tipificado en la ley y en los demás preceptos legales, pues se suele presentar dilación en cuanto a la libertad de la persona.

Cualquier restricción que no cumpla con los requisitos suficientes supone para la Corte la violación del artículo 7.3 de la Convención Americana de Derechos Humanos: "Nadie puede ser sometido a detención o encarcelamiento arbitrarios" (CADH, 1969, p.4). No obstante, es necesario deslindar algunos requisitos establecidos por la CIDH con respecto a que dichas medidas de privación o restricción no sean arbitrarias:

1. Que la finalidad de las medidas que priven o restrinjan la libertad sean legítimas.

2. Que las finalidades adoptadas sean idóneas para cumplir los fines.

3. Que las medidas sean necesarias y que no existan otras menos gravosas.

4. Que las medidas sean estrictamente proporcionales.

Es importante contrastar la aprehensión y el arresto, pues implican cosas diferentes y suelen confundirse al momento de contextualizarlas, además son acciones que conllevan a la vulneración inmediata del derecho de libertad individual y que comportan causas ilegales.

La aprehensión es una acción de captura de autoridades policiales u otros que autorice la ley. Este proceso se origina sin necesidad de una orden judicial con el fin de presentar al aprehendido ante autoridades competentes. No obstante, no se cuenta con un criterio claro de esa figura, pero el Código Penal lo define en casos de flagrancia:

Procedimiento en caso de flagrancia. Cuando sea una autoridad la que realice la captura deberá conducir al aprehendido inmediatamente o a más tardar en el término de la distancia, ante la Fiscalía General de la Nación. Cuando sea un particular quien realiza la aprehensión deberá conducir al aprehendido en el término de la distancia ante cualquier autoridad de policía. Esta identificará al aprehendido, recibirá un informe detallado de las circunstancias en que se produjo la captura, y pondrá al capturado dentro del mismo plazo a disposición de la Fiscalía General de la Nación. (Ley 906 del 2004, art 302)

Este precepto legal, en algunos casos se torna ilegal efectuado por particulares o autoridades competentes. Puede suceder que, al momento de la aprehensión del individuo, la persona que accionó no tenía la autorización previamente establecida por la ley o, por otro lado, puede que el aprehendido no tuviera conductas que merecieran la aprehensión. Así, 
se requieren tres cosas: autorización judicial previa, por orden y facultad investigativa de la fiscalía y captura en flagrancia. Estos requerimientos configuran la regla general que permite accionar. Sin embargo, se presentan situaciones diferentes como sentencia firme, fuga del individuo o auto de prisión preventiva. La figura de la aprehensión tiene por fin el de privar de su libertad a la persona que realiza el acto ilícito, siempre que tal esté tipificado como delito

Otra de las formas que conforma el marco de la detención ilegal, es el arresto, que se conduce como medida coercitiva proferida por el juez en etapa de investigación o con indicios graves y material probatorio. En este se revocan las libertades del implicado al ser acusado formalmente y puesto en conocimiento del delito cometido.

Es preciso establecer algunos presupuestos generales para proceder al arresto de una persona:

1. Hay certeza de que la persona sobre la cual recae la medida es la que cometió el delito.

2. Si aún no se han individualizado los autores del hecho cometido

3. Si se tienen indicios de que la persona cometió el delito.

4. Si no se ejecuta el arresto se pondría en peligro los avances de la investigación.

En el entendido de las figuras que se trazan anteriormente, resulta importante, como Loyola y Muñoz mencionan:

El reconocido Doctor en Derecho y Ciencias Sociales el señor Cafferata Nores, José I. se encarga de definir al arresto como: "Es el estado fugaz de privación de la libertad dispuesto por un órgano judicial cuando en los primeros momentos de la investigación de un hecho delictuoso en que hubieran intervenido varias personas no fuera posible individualizar a los responsables y a los testigos, y no pueda dejarse de proceder sin peligro para la investigación. (2016, p8)

Frente a la carencia de un concepto sólido de detención arbitraria o ilegal es necesario situar algunos principios, como antes, que intervienen en dicha actuación, esta vez establecidos por la Organización de los Estados de América:

1. Trato Humano.

2. Igualdad y no discriminación.

3. Principio básico (libertad personal).

4. Excepcionalidad de la privación preventiva de la libertad.

5. Medidas alternativas o sustitutivas a la privación de libertad.

6. Legalidad. 
7. Debido proceso legal.

8. Control judicial y ejecución penal.

9. Petición y respuesta.

10. Medidas especiales para las personas con discapacidades mentales.

\section{DETENCIÓN ILEGAL EN MENORES DE EDAD}

\section{a. Derecho romano}

En el derecho romano carecían de capacidad en materia penal para los infantes o impúberes. Sin embargo, establecían por regla general imputar a un menor por una conducta ilícita cuando este ya había alcanzado la pubertad; es decir, varones a los 14 años y mujeres a los 12 años. Es importante resaltar que no se contaba con un sistema aparte para el procesamiento de menores o púberes. En efecto, solo se concedía un trato diferente frente a personas mayores de edad.

Se consideraba que los menores que no alcanzaban la pubertad carecían de capacidad de obrar por lo que no se les aplicaba la ley vigente en aquel momento. Esta clasificación de capacidad en la población infante, es decir, en los menores de edad, se realizaba por medio de la ley natural, es allí donde nace la diferencia entre púber e impúber.

En efecto, las Partidas ofrecen, sin duda, una ordenación sistemática de la minoría de edad penal, distinguiendo dos límites de edad, a saber: uno, para los delitos que afectan a la honestidad, delitos de lujuria, en donde la irresponsabilidad alcanza hasta los 14 años en el hombre y 12 en la mujer, y otro, para los demás delitos, en cuyo caso, la minoría de edad penal se sitúa en los 10 años y medio. Los menores de estas edades venían excluidos de responsabilidad criminal, por lo que no se les podía acusar de ningún "yerro" que hiciesen, ni se les podía aplicar pena alguna. (Alemán, 2007, p.32)

De acuerdo a lo anterior, el Derecho romano justiniano distinguió varios límites de edad asignados a los infantes, impúberes y en período de la pubertad. Aquí no se especificaba una detención propia de los púberes, puesto que, como se ha mencionado no se contaba aún con un sistema diferente. Las acciones más próximas que tomaban allí era:

1. A los impúberes no se les podía imponer ningún tipo de pena, así que recibían un castigo como fin de amonestación.

2. Imponían a los ladrones menores, que se azotase según criterio del pretor y posteriormente la reparación del daño ocasionado. 


\section{b. Derecho germánico}

En el Derecho germánico, la condición para establecer la minoría penal era de 12 años. Entre tanto, se tenían en cuenta algunos criterios como: causa de responsabilidad, resarcimiento de la pena y la transmisión de la responsabilidad a la familia. Así, las acciones que tomaban contra los niños que incurrían en delitos eran transmitir la obligación al padre o la persona que estuviera a cargo del menor, esta debía pagar una composición.

Es preciso relacionar la trascendencia social que portaban las comunidades, en cuanto a los derechos, costumbres y diferentes sacrificios. Todo esto, con un fin específico, que era la responsabilidad colectiva como resarcimiento de daños.

Los avances del derecho germánico no contenían un sistema exclusivo en cuanto al tratamiento penal del menor infractor, sino que las formas de castigo se realizaban por la comunidad y las formas de resarcimiento, en tiempos posteriores, incluyó la indemnización civil como obtención de la paz del ofensor. Aquella medida de pago se denominaba el wergeld (rescate, indemnización, satisfacción).

\section{c. Derecho canónico}

El Derecho canónico con influencia en el Derecho romano y las tablas de edad, consideraba exentos de responsabilidad en materia penal a los menores de 7 años, también denominados infantes.

Así las cosas, existía una excepción a la regla general, puesto que, si los infantes obraban con discernimiento en la comisión de un delito, se les imponía una pena atenuada por tratarse de menores de 7 años. También se les concedía preferencia con la capacidad que contaban para obrar.

Un aporte muy importante, Cruz y Cruz (2007) afirma:

El derecho canónico se apegó, por lo general, a los criterios establecidos por el derecho romano imperial, sobre todo en lo relativo a la presunción de la irresponsabilidad, la diferenciación en los grados de responsabilidad según la situación específica del menor (infante próxima o pubertate próxima), la valoración de la capacidad de discernimiento, con posibilidad de atribución de dolo y una atenuación genérica de las penas, dejada al arbitrio judicial. (p 5)

Las casas de corrección se comienzan a tratar en este periodo. Se puede evidenciar una detención la cual variaba con la gravedad del delito que comete el menor infractor, así como las penas atenuadas establecidas en el Código de 1822. Es importante la consagración positiva del Derecho, puesto que comienzan a reconocer la prohibición de la pena de muerte a menores de 17 años, torturas o destierros. En consecuencia, se contó con la vigencia del código hasta el año siguiente, después de varios intentos se contó en 1848 con el nuevo código penal. 


\section{d. Legislación colombiana}

Ley 98 de 1920

Este precepto originó la Jurisdicción especial para menores, con la creación de juzgados, casa de reforma y corrección de menores atendiendo al modelo tutelar. Así mismo, el Código de Procedimiento Penal del año 1987 continuó con el canon para menores de edad.

Esta mencionada ley asignó un Juez de menores con procedimientos verbales, y ágiles para la acción de diferentes procesos tanto de investigación y penalidad. El modelo tutelar con que inició esta disposición frente al menor infractor comprende la protección y preservación de menores entre los siete y diecisiete años.

Las medidas que acciona el Juez de menores implican en menor medida la absolución total de la pena, previa amonestación al menor o a sus padres, la permanencia del menor en su residencia bajo una continua vigilancia o internamiento en una casa de reforma y corrección de menores, como lo estipula la ley 98 de 1920. Pese al contenido de la presente ley no presenta alguna disposición de la prohibición de los malos tratos o acciones arbitrarias por parte de las autoridades al momento de la detención o retención del menor.

\section{Ley 83 de 1946}

Esta ley orgánica de la defensa del niño, surge de la necesidad de la nueva postura catalogada Defensa del niño, puesto que el Código Penal en ese momento vigente no garantizaba la protección del menor y es así como este precepto elimina las edades fijadas por la anterior ley como línea para accionar, allí se consignan la detención arbitraria y las acciones legales que se toman si se infringen los derechos del menor.

Artículo 14. Prohíbase detener a un menor de diez y ocho años en lugar distinto de los expresados en el artículo 12, o de los establecimientos especiales para menores. La violación de esta prohibición hará incurrir al funcionario que dé la orden de detención y al Alcalde o jefe del respectivo establecimiento, en la pérdida del empleo y en la interdicción del ejercicio de derechos y funciones públicas durante un año, sanción que le será impuesta sumariamente por el superior respectivo, con la sola vista de la prueba de que se ha incurrido en la infracción. (Ley 83, 1946, art.14)

\section{Decreto 1818 de 1964}

Esta ley se denomina Protección Social del Menor y la Familia, y tiene sus inicios con la organización y división de los menores que contempla Ministerio de Justicia. Esta Ley establece lineamientos con respecto de la edad del menor, al mencionar que los menores de 12 años ya no son competencia del Juez de Menores. 
Ahora bien, la competencia de la Jurisdicción de menores comprende entre los 12 y 18 años para el tratamiento de comisión de delitos, situación de abandono y peligro físico, moral o psicológico. Por otro lado, la detención que trata la presente ley se refiere a casa de observación por un periodo no mayor a noventa días, infiriendo que si se sobrepasa este límite, la detención se transfigura en ilegal.

Ley 75 de 1968

La presente ley la crea el Instituto Colombiano de Bienestar Familiar (ICBF). Suprime la división antes mencionada de menores en el Ministerio de Justicia y se adscribe la competencia en menores de 12 años en adelante que cometen delitos.

La edad límite que establece la presente ley para asignar competencia a los jueces municipales que menciona la citada Ley es de 16 a 18 años. Si el infractor es menor de 16 años, la competencia se traslada al Juez de Menores; en todo caso, el Juez aplicará las medidas mencionadas en la Ley 83 de 1946, artículo 35.

Hay que destacar la función del ICBF, tanto en la filiación como en sus propias funciones y las competencias que traslada el Ministerio de Justicia.

Código Penal y Código de Procedimiento Penal (2000 y 2006)

El actual código modifica nuevamente la edad que determina la responsabilidad penal y civil de los menores infractores, siendo de 14 a 18 años. La carta política reconoce que los Derechos de los menores priman sobre los de los adultos, pues tienen especial protección de las condiciones de su desarrollo y en particular, la intervención por parte de las autoridades al momento de la retención del menor, puesto que se reconoce un peligro mayor al practicar detenciones ilegales en sujetos de indefensión e inocencia.

Los menores de edad, en efecto, están sujetos a un modelo de protección integral, como se ostenta en la Convención de Derechos del Niño de 1989. Se reconoce a los niños como sujetos de derechos, lo que significa que los adultos están directamente encargados y portan la responsabilidad de garantizar este reconocimiento, así como, cada el Estado Parte que se suscribe, a continuación, se contiene una serie de principios y normas que se fundamentan en tres aspectos:

1. Derechos universales

2. Derechos indivisibles

3. Derechos interdependientes

Ley 1098 de 2006

El Código de Infancia y Adolescencia contiene los instrumentos relacionados con la infancia y la adolescencia. Estos son principios, normas, 
procedimientos, entes administrativos que accionan juzgamiento de delitos, medidas privativas de libertad. También existe el Sistema de Responsabilidad Penal Adolescente (SRPA), del que se habla más adelante en el presente texto.

La autora Díaz (2009) desglosa los principales avances del Código de Infancia y Adolescencia (CIA) en materia de Responsabilidad Penal en menores, como son:

1. La instauración del modelo de responsabilidad del menor que infringe la ley que contienen medidas tanto pedagógicas como específicas y diferenciadas con respecto de su protección integral.

2. Clasificación de edad de menores para actuar frente al proceso penal (menores de 14 años que gozan de exclusión de responsabilidad penal y mayores de 14 años para exigir tal responsabilidad).

3. Reconocimiento de la Jurisdicción indígena en su artículo 156 del CIA con respecto a las comunidades indígenas, que poseen disposiciones especiales para juzgar.

Decreto 860 de 2010

Este decreto reglamentó el Código de la Infancia y la Adolescencia, imponiendo obligaciones para evitar conductas punibles ocasionadas por menores de edad. Una de las finalidades de este decreto es puntualizar los procesos armónicos integrales del niño, los asuntos de conciliación y reparación de daños ocasionados por el menor y las medidas pedagógicas con el fin de concientizarlo de las conductas realizadas.

Ley estatutaria 1622 de 2013

Esta ley contiene un aporte significativo con relación al ejercicio pleno de la ciudadanía adolescente y el desarrollo de su participación. El artículo 7 hace referencia a la noción de prevención que busca evitar situaciones que vulneren los derechos fundamentales de los menores.

Su relevancia en el tema en particular es la estipulación del tratamiento y procesos de los jóvenes en conflicto con la ley. De igual forma, los procesos de resocialización y reintegración a la sociedad que ayuden al correcto desarrollo de los procesos asignados en materia penal y también a la justicia restaurativa y lo que concierne a las orientaciones y aspectos pedagógicos del menor.

Es necesario unificar aspectos procesales que son regulados por los mandatos mencionados en otros y establecer su modo de aplicación, iniciado de forma general y continuando de forma específica para evidenciar sus diferencias. 


\section{PRESUPUESTOS PROCESALES QUE EVITAN LA ILEGALI- DAD DE LA DETENCIÓN}

\section{Orden Judicial Previa}

La orden judicial previa estipula, para supuestas conductas delictivas, un modelo de investigación en el que previamente se necesita un mandato proferido por una autoridad competente. También es indispensable para actuaciones como acusación, defensa, juzgamiento y demás etapas procesales.

La esencia de la orden judicial previa es el medio idóneo para la restricción de la privacidad en ejecuciones como registro y allanamiento, retención de correspondencia o correo, recuperación de información por internet, interceptación de telefonía y comunicaciones, vigilancia de implicados y bienes, infiltración de organizaciones criminales, incautación de bienes, entre otros. Sin embargo, el tema que nos compete es la acción ilegal de la detención, retención o aprehensión de un individuo y su sustento legal reposa implícitamente en la Constitución Política de Colombia de 1991 en su artículo 28, el cual enfatiza que toda persona es libre. En caso contrario, si se interviene en el mismo debe estar expreso por mandamiento escrito de la autoridad judicial competente, con formalidades de ley.

De igual forma, el Código de Procedimiento Penal (Ley 906 de 2004) en su artículo 2 y 297, resalta el derecho fundamental de la libertad y que no puede ser interrumpido sino en virtud de un mandamiento escrito de autoridad judicial competente. Así mismo, en cuestiones de requisitos generales para la captura, es indispensable una orden escrita y proferida por un Juez de Control de Garantías.

\section{Flagrancia}

Esta figura no se entiende como requisito de ley sino como una excepción a la regla de la orden previamente proferida, pues 1 acción o conducta delictiva implica que el individuo es sorprendido en el momento preciso de su realización permitiendo su captura posterior. Significa que no es necesaria una orden judicial, puesto que es un tipo de evidencia sensorial, y esta sirve para llevar el individuo al cuerpo policial o lugar correspondiente para que se inicie la investigación idónea.

Se dice en la ley 600 del 2000 en el artículo 345 que se entiende que hay flagrancia cuando se presentan tres alternativas: 1) es sorprendido y aprehendido al momento de la realización de la conducta, 2) es identificado o individualizado el sujeto al momento de cometer la conducta punible y aprehendido después de persecución. 3) Es capturada la persona con objetos, instrumentos o huellas que indican que momentos antes cometió un delito. Estos mismos requisitos se visualizan en la ley 906 de 2004 en su artículo 301. 


\section{Públicamente requerido}

Esta figura es accionada cuando es públicamente requerida por una autoridad competente. No obstante, se aplican las mismas disposiciones de la flagrancia. Su estipulación se encuentra en la ley 600 del 2000, Código de Procedimiento Penal, en el artículo 348, que precisa la captura públicamente requerida.

Se presentan más requisitos para la detención o detención preventiva del individuo, como su identificación o individualización, exposición sucinta de los hechos y objeto de imputación, entre otros. También está la orden de detención ejecutoriada por la Policía Nacional, y finalmente, el material probatorio conducente.

Todo esto tiene como fin esclarecer la naturaleza de la detención y el objeto con que se realiza. De otro modo, para que se presente detención ilegal por parte de la autoridad pública, debe presentarse la ausencia de todos los presupuestos materiales o formales tipificados por la ley.

\section{Solicitud de medida de aseguramiento por parte del fiscal}

La ley de procedimiento penal (Ley 906 de 2004) le otorga facultades al fiscal de solicitar medida de aseguramiento a un implicado e incide en la restricción de la libertad personal, permitiendo que el sujeto que solicite la medida otorgue suficientes presupuestos legales ante el Juez de Control de Garantías.

\section{Captura facultativa}

Es una figura que posibilita al fiscal en cuestiones de indagatoria a proferir una orden escrita de captura en cuanto a delitos sancionados con pena cuyo mínimo sea de dos (2) años y siguientes, pues es indispensable que la etapa del proceso que se esté agotando, conforme a lo establecido en el Código Penal Colombiano, se vincule a las partes solicitadas.

\section{Elementos materiales probatorios}

El artículo 308 del Código de Procedimiento Penal menciona tres (3) requisitos que debe cumplir el imputado. Adicional a eso el Juez de Control de Garantías verifica los elementos materiales probatorios, evidencias físicas e información obtenida legalmente para que posibilite inferir la responsabilidad del imputado y que se cumplan aspectos como: que la medida de aseguramiento se muestre necesaria para evitar la obstrucción de la justicia, que constituya un peligro para la seguridad de las personas y, finalmente, que se demuestre que el implicado no podrá asistir a la audiencia o a las etapas procesales. No obstante, no se puede desconocer el artículo 313 del mismo código que trata de la imposición de la medida de aseguramiento; es decir, que sean conductas tipificadas que requieran de medida privativa de libertad. 
Más allá de las situaciones que acompañan la detención ilegal, la falta de la formalización y cumplimiento de los requisitos de ley se aplican también en las medidas provisionales, medidas cautelares y todas aquellas similares. Sin embargo, es importante analizar la presunción de inocencia puesto que este precepto es vital al igual que el derecho de libertad personal como bien jurídico que más adelante se explicará.

Diferentes postulados normativos y teóricos relacionan los presupuestos necesarios para evitar la ilegalidad, no obstante, a continuación se explica explicar el origen de este fenómeno en sujetos de especial protección constitucional. De esta manera, se podrá explicar desde el daño antijurídico cómo se pueden prever este tipo de conductas por parte de los responsables.

\section{RESPONSABILIDAD DEL ESTADO POR DETENCIÓN ILEGAL EN MENORES}

El objetivo del Estado es perseguir el bienestar de la sociedad, mediante la adopción de diferentes procedimientos, encaminada a la libertad, justicia y paz por medio de órganos, funcionarios y agentes designados por el mismo. Sin embargo, hay acciones que permiten comprender la problemática de la existencia de la detención ilegal, en particular de menores de edad en Colombia.

La detención ilegal se trata, en primera medida, de un error en la prestación del servicio; es decir, la ineficiencia al momento de privar de la libertad a un individuo, convirtiéndose en injusticia. El estado reconoce que es un daño el cual el particular no está obligado a soportar. Es así como la responsabilidad estatal tiene la obligación de actuar en sus diferentes regímenes, que más adelante se mencionan. De acuerdo a la Agencia Nacional de Defensa Jurídica del Estado:

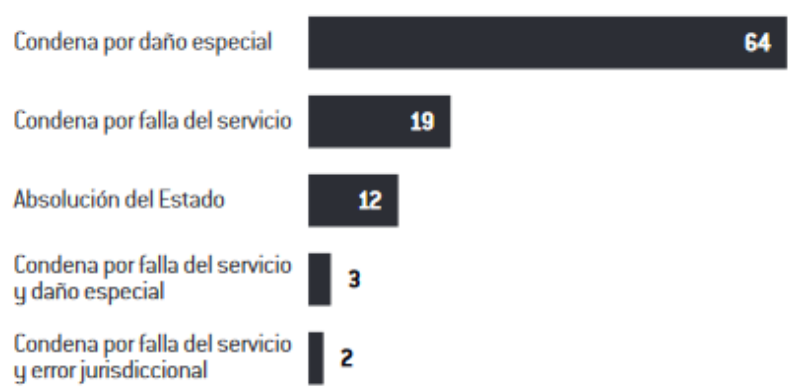

Figura 1. Participación de los procesos estudiados por fundamentos de responsabilidad estatal, en porcentajes.

Fuente: Agencia Nacional de Defesa Jurídica del Estado, 2013, p. 10. 
El reconocimiento de la responsabilidad del Estado por la privación injusta de la libertad es uno de los avances jurídicos más significativo que ha tenido cualquier sociedad, pues la libertad es uno de los derechos fundamentales de las personas, el cual está matizado con otras prerrogativas inherentes a la persona, como la honra, la dignidad, intimidad, etc., las cuales, indudablemente, se ven menoscabadas cuando una persona se ve recluida en un establecimiento carcelario; y aún más, cuando ello se ha realizado injustamente (Prato, 2016, p.30).

Diferentes sistemas de responsabilidad estatal y su obligación de responder por los daños han sido reconocidos por el ordenamiento jurídico, partiendo de la Constitución Política de Colombia de 1991, (art. 90).

La falla del servicio ha sido el principal título jurídico y origen de la detención ilegal tanto en adultos como en menores, puesto que se violan contenidos legales, reglamentarios, sustanciales, y similares. En este sentido, el Estado no asegura dichas deficiencias, los deberes y derechos sociales y particulares.

Con respecto de las detenciones injustas e ilegales, el Estado debe reconocer el perjuicio moral tanto para la víctima como a sus familiares cercanos. Este aspecto patrimonial se acciona mediante una tasación diferenciada; para esto, el valor se determina por el factor temporal el daño causado a la víctima. Generalmente se habla de 5.1 salarios mínimos mensuales legales vigentes. Sin embargo, esta cifra es subjetiva; basta con analizar el nexo causal y el daño. Más allá del cálculo de cifras, por cada día de reclusión en donde sea que se encuentre el menor, lo afecta tanto psicológicamente como físicamente.

\section{ELEMENTOS ESTRUCTURALES DE LA RESPONSABILI- DAD PATRIMONIAL DEL ESTADO}

El artículo 90 de la Constitución Política de Colombia de 1991 establece dos factores de responsabilidad patrimonial:

\section{Que haya un daño antijurídico}

Sucede cuando se priva de la libertad al menor y al tiempo es absuelto comprobando que no tuvo ningún gravo de culpabilidad en el hecho que le imputaron. Realmente no existe una definición expresa sobre daño antijurídico. Sin embargo, reiteradas veces el Consejo de Estado lo enlaza con la responsabilidad plenamente objetiva del Estado. Esta responsabilidad administrativa se traduce en una falla del servicio probada la cual el menor no tiene el deber jurídico de soportarla. (Serrano y Tejada, 2014)

\section{La imputación del daño en el Estado}

En materia penal, las nociones de causalidad e imputación resultan confusas a la hora de aplicarlas, toda vez que no se puede hacer una referencia a tal causalidad porque la misma está ligada una la fuerza mayor, caso 
fortuito, hecho de un tercero o culpa exclusiva de la víctima, entendiendo que, esta figura no evidencia un nexo entre la víctima y el culpable. En otras palabras, a diferencia de en el daño antijurídico, la imputación son los elementos necesarios que permiten atribuir la responsabilidad del daño al Estado. En suma, este último fenómeno se da en la falla del servicio, actividad peligrosa o daño especial y sirve para evidenciar el nexo causal entre el daño y el sujeto en este caso el Estado. (Serrano y Tejada, 2014)

En Colombia, la regulación de responsabilidad Estatal por detención ilegal se ha ido consolidando con los preceptos internacionales tanto de menores como de adultos, estos instrumentos, en los que se ahonda más adelante, han permitido no solo absolver al menor, s no también resarcir el daño patrimonialmente.

\section{DETENCIÓN ILEGAL EN SUJETOS DE ESPECIAL PRO- TECCIÓN CONSTITUCIONAL}

\section{Menores de edad}

La detención como se ha venido mencionado, es una medida coercitiva que se plantea desde nuestro ordenamiento jurídico en dos momentos: el primero como medida cautelar cuando se pretende poner al individuo detenido a disposición de una autoridad judicial competente. El segundo como medida ejecutiva cuando se pretende constituir en prisión al individuo. Sin embargo, independiente de la persona (hombre, mujer, menor de edad, incapacitado $u$ otro), se aplican distintos presupuestos procesales para perfeccionar la figura. Ahora bien, con respecto de la detención ilegal en menores de edad, menciona el Código de la Infancia y de la adolescencia:

Artículo 20. Derechos de Protección. Los niños, las niñas y los adolescentes serán protegidos contra:

Parágrafo 8: "La tortura y toda clase de tratos y penas crueles, inhumanos, humillantes y degradantes, la desaparición forzada y la detención arbitraria" (Ley 1098, 2006, art.20).

Artículo 21. Derecho a la libertad y seguridad personal: Los niños, las niñas y los adolescentes no podrán ser detenidos ni privados de su libertad, salvo por las causas y con arreglo a los procedimientos previamente definidos en el presente código (Ley 1098, 2006, art.21).

Las acciones de restricción de libertad, son totalmente distintas a las habituales en personas mayores de edad.

\section{Menores de 14 años que cometen infracciones penales}

La responsabilidad penal establecida para adolescentes en el Código de Infancia y Adolescencia expresa en su artículo 143 que no les asiste nin- 
gún tipo de responsabilidad criminal a los menores de 14 años, es decir, no serán juzgados ni declarados penalmente.

La acción que toma la autoridad pertinente es detener al menor con el fin de aplicar medidas para el restablecimiento de sus derechos, tanto de sus garantías como procesos de educación y protección emitidos por el Sistema Nacional de Bienestar Familiar. En efecto, después de realizada la detención, se pondrá al menor a disposición de los padres

En cuanto a la detención que se realiza, es importante que se practique con efectos legales, expresando la autoridad con un lenguaje entendible. Respecto a los perjudicados o víctimas de las acciones ocasionadas por un menor de 14 años, puede reclamarse la responsabilidad que ocasionó el menor a sus padres directamente.

La figura de "niños y niñas en conflicto con la ley" relacionada con la protección de infancia por la organización líder UNICEF, permiten realizar un estudio crítico del perfil del menor al momento de realizar dichas conductas.

\section{Perfil del menor}

La mayoría de los niños y niñas en conflicto con la ley han cometido pequeños delitos, o faltas menores como vagancia, ausencia injustificada de la escuela, mendicidad o consumo de alcohol. A algunas de estas faltas se las conoce como "delitos en razón de la condición personal" y no se consideran criminales cuando las cometen adultos. Además, algunos niños que incurren en una conducta criminal lo han hecho debido a la utilización o coerción de adultos. Con demasiada frecuencia, los prejuicios relacionados con la raza, el origen étnico o la condición social o económica pueden hacer que un niño entre en conflicto con la ley incluso cuando no ha cometido delito alguno, o provocar un trato violento por parte de los funcionarios encargados de hacer cumplir la ley. (UNICEF, s.f, p.1)

En la esfera íntima del menor se ve reflejada la violencia, los malos tratos, la explotación y la marginación, entre otros aspectos que configuran situaciones episódicas en la mayoría de casos que dan lugar a la detención.

Según la información suministrada por la Subdirección de Responsabilidad Penal para Adolescentes del ICBF, desde la implementación progresiva del SRPA del 8 de marzo del 2007 hasta el 31 de diciembre del 2014 han ingresado 172.530 adolescentes; 29.644 en el último año de la implementación, correspondiendo en su mayoría al sexo masculino, al representar el $88,4 \%$, mientras que de sexo femenino alcanza el $11,6 \%$ (ICBF, 2015, p.13). UNICEF plantea diferentes alternativas de detención que se deben aplicar ante los conflictos delictivos con menores de edad. 


\section{COMPROMISO DEL GOBIERNO}

Accionar nuevas políticas de privación de libertad en menores de edad con el fin de garantizar el debido proceso, el derecho a la defensa y la justicia juvenil. El compromiso también va encaminado a evitar que las autoridades que efectúen la detención no obedezcan los parámetros o se deban aplicar otras medidas de restricción.

\section{LEGISLACIÓN INTERNACIONAL EN EL ÁMBITO LOCAL}

Los organismos internacionales que propenden a la protección de los niños, niñas y adolescentes, deben adecuar el ordenamiento jurídico interno para evitar tratos crueles hacia los menores, acciones arbitrarias que ejecuten las autoridades o juzgamientos presuntuosos sin suficientes evidencias y pruebas que demuestren la responsabilidad penal.

\section{SEGUIMIENTO Y SUPERVISIÓN}

Es importante tener presentes los procedimientos judiciales de quienes tiene a cargo a los menores investigados, tanto de los detenidos, como de los que se encuentran en audiencias. También hay que realizar la revisión adecuada de sentencias ,puesto que el debido proceso debe de estar inmerso en las acciones de detención que se realizaron, los procesos sociales con que cuenta el menor y que no se permita exponerlos ante ningún riesgo.

\section{Mayores de 14 años que cometen infracciones penales}

El SRPA se crea con el fin de contar con una figura pedagógica que va ligada con la justicia restaurativa, para contar con diferentes mecanismos de justicia de forma idónea como conciliación, mediación y principio de oportunidad. A su vez cuenta con sanciones que aplican a los menores de edad con la finalidad de: proteger, restaurar y educar.

El Código de la Infancia y la Adolescencia propone algunos requisitos que relacionan someramente la detención legal en Colombia de menores de edad.

\section{MEDIDAS DE ASEGURAMIENTO EN MENORES DE EDAD}

Existen circunstancias imparciales para decretar alguna medida de aseguramiento en contra del menor. Sin la existencia de ellas, la ejecución de detención no cumple los parámetros establecidos por el Código de Infancia y Adolescencia, ni los diferentes preceptos inmersos en el ordenamiento jurídico:

A) Riesgo razonable de que el adolescente eluda el proceso. B) Destrucción u Obstaculización de pruebas. C) Peligro para la víctima, la sociedad y para él mismo. 
La restricción de libertad en menores y adolescentes reconoce el ordenamiento interno en el que se excluye y prohíbe toda clase de tratos crueles, maltratos y detenciones arbitrarias e ilegales, considerando la detención el último recurso que actúa la administración.

- $\quad$ El sistema de Responsabilidad Penal Adolescente ejecuta la Medida de Internamiento Preventivo, con un tiempo máximo de cinco (5) meses, únicamente se cuenta con esta medida de privación que es desarrollada mediante el contexto normativo, denominado Sanciones.

- $\quad$ Este es un término perentorio y no se puede extralimitar.

- El Código de la Infancia y la Adolescencia en el artículo 162, menciona dos medidas de privación de libertad: Libertad Provisional y Detención Domiciliaria. Se ejecutan cuando se carece de establecimientos especiales para recluir al menor.

No se cuentan con más medidas sino las establecidas para adultos en el Código de Procedimiento Penal, pero se debe tener en cuenta que la privación de libertad es una regla excepcional al derecho de libertad individual y por lo tanto se debe acoger a los parámetros establecidos por la Jurisdicción especial para menores para evitar algún tipo de transgresión de Derechos Humanos. Finalmente, las medidas que se apliquen tienen que ser congruentes con el procedimiento para menores de edad.

La Medida de Detención en niños, niñas y adolescentes, no se cuentan con más alternativas para accionar, tampoco reglas especiales, más que condiciones subjetivas para restringir la libertad del menor infractor.

\section{REGLAS DE PROTECCIÓN DE DERECHOS DE MENORES DE EDAD PRIVADOS DE LA LIBERTAD}

Las condiciones de detención de un menor que no haya sido juzgado deberán ajustarse a las reglas siguientes, y a otras disposiciones concretas que resulten necesarias y apropiadas, dadas las exigencias de la presunción de inocencia, la duración de la detención y la condición jurídica y circunstancias de los menores. Entre esas disposiciones figurarán las siguientes, sin que esta enumeración tenga carácter taxativo:

a. Los menores tendrán derecho al asesoramiento jurídico y podrán solicitar asistencia jurídica gratuita, cuando ésta exista, y comunicarse regularmente con sus asesores jurídicos. Deberá respetarse el carácter privado y confidencial de esas comunicaciones;

b. Cuando sea posible, deberá darse a los menores la oportunidad de efectuar un trabajo remunerado y de proseguir sus estudios o capacitación, pero no serán obligados a hacerlo. En ningún caso se mantendrá la detención por razones de trabajo, de estudios o de capacitación;

c. Los menores estarán autorizados a recibir y conservar material de en- 
tretenimiento y recreo que sea compatible con los intereses de la administración de justicia. (ONU, 1990 B, p.6)

Las condiciones en que se le deben brindar en el tratamiento a los menores que tienen conflicto con la ley son dirigidas por la de las Naciones Unidas (ONU), siendo obligación de los Estados incorporar estas estipulaciones en el ordenamiento interno con el fin de evitar cualquier perjuicio a los menores.

\section{ORDEN DE AUTORIDAD JUDICIAL, ADMINISTRATIVA O CUAL- QUIER AUTORIDAD COMPETENTE}

Para recluir a un menor en un centro de detención es importante que se tenga una orden válida para realizarlo, debe estar plenamente detallada y consignada en el registro del menor y expediente. Sin la misma, no procede ningún tipo de detención y se transforma en ilegal la acción.

\section{ANTECEDENTES}

Los informes médicos, registros jurídicos, procesos disciplinarios, datos personales y similares. Solo pueden tener conocimiento de estos las personas autorizadas. El menor tiene derecho de impugnar los hechos imprecisos en su expediente (las afirmaciones presuntuosas o hipótesis de documentos incongruentes, inexactos, alterados por terceros).

\section{INGRESO AL INTERNAMIENTO}

Es importante contar con un registro claro de los menores detenidos en los diferentes centros especializados autorizados. Esto permite tener claridad de los procesos que se adelantan contra los mismos, así como también de los traslados efectuados.

La información que debe incluir el registro, consta de los datos personales del menor, las circunstancias de detención, día; fecha y hora de la realización del ingreso, registro, traslado y de la liberación, notificación idónea a los padres, tutores, Ministerio Público o ICBF de los procesos adelantados e información continua del estado del menor (condición de salud, física, moral y el suministro de sustancias alucinógenas, consumo de alcohol, entre otras).

\section{ASIGNACIÓN DE HÁBITAT AL MENOR}

Una vez admitido al centro de detención es importante realizarle estudios psicológicos y sociológicos para proceder a garantizar un hábitat adecuado con las condiciones mínimas y necesidades de calidad de vida, así como las orientaciones y tratamientos durante la permanencia en la institución. Es importante preservar la integridad del menor y cumplir con todas las etapas y fases por los funcionarios encargados, evitando todo tipo de riesgo en la permanencia o en las acciones producidas. 
En últimas, las condiciones físicas de las instituciones se debe garantizar la dignidad humana recordando que el menor debe contar con una atención especializada, procurándose una adecuada rehabilitación como objetivo principal.

\section{EDUCACIÓN}

El nivel de escolaridad que tenga, debe continuarse en el centro de detención hasta su culminación, puesto que, la educación es un derecho fundamental que tiene estrecha relación con la rehabilitación. En otras palabras, la reinserción a la sociedad comprende un cúmulo de tratamientos y procesos para integrarlo nuevamente. Los funcionarios deben velar por el buen cumplimiento y atender las dificultades de menores con problemas de aprendizaje, cognitivos y cualquier otro que impida el funcionamiento de los métodos asignados para la rehabilitación.

\section{PROCESOS DE ESPARCIMIENTO}

La recreación hace parte el tratamiento especial al menor. De hecho, para que prospere la rehabilitación, son necesarias las actividades recreativas, pues permiten transformar las secuelas y así se posibilita restituir en el infante o adolescente un comportamiento adecuado.

\section{PROHIBICIÓN DE COERCIÓN}

Las modalidades de coacción o uso de la fuerza, impiden el desarrollo del menor en el centro de detención y violan los derechos constitucionales. Entre tanto, se deben emplear diferentes medios de control que conduzcan a la protección de la integridad y dignidad del menor.

\section{INSTRUMENTOS INTERNACIONALES DE PROTECCIÓN DEL MENOR EN LA DETENCIÓN}

\section{Declaración Universal de los Derechos Humanos (1948)}

Este tratado internacional busca la protección de los menores que infringen la ley penal, específicamente los artículos (3, 5, 12,13 y 17). Se otorgan garantías en situación de detención a esta población menor, como es el derecho a la vida, libertad, seguridad, entre otros. De igual manera prohíbe lo relacionado a los tratos inhumanos, arbitrarios, crueles y todos los que constituyen bienes jurídicos que garantiza la Ley Penal, en tanto que, protege la salud, integridad, entre otros.

\section{Declaración de los Derechos del Niño (1959)}

La Asamblea General de las Naciones Unidas aprueba esta declaración con el fin de respaldar la connotación "Sujetos de derechos" otorgando derechos específicos a los menores. Establece 10 principios garantes de protección y también en sus disposiciones se pretende prevenir las conductas punibles ocasionadas por los menores. 


\section{Pacto Internacional de Derechos Civiles y Políticos (1966)}

Este tratado relaciona el respeto por el derecho a la vida, prohibiendo así los tratos crueles, las torturas y, en especial, a no ser interferido de manera ilegal o arbitraria en su vida privada. Esto va ligado al artículo 24 de la mencionada disposición, que se refiere a la protección y cumplimiento de derechos humanos de los niños y niñas.

\section{Convención Interamericana de Derechos Humanos, Pacto de San José (1969)}

Esta protege derechos relativos a la vida, la libertad, la integridad, la dignidad, la honra y similares de la sociedad en general. En particular, el artículo 19 relaciona las medidas de protección frente a los menores de edad. Entre ellas se incluyen las medidas de privación de libertad que se requieran por parte del Estado, la familia y la sociedad.

\section{Reglas de la ONU para la Prevención de la Delincuencia Juvenil: Reglas de Riad (1990)}

Las directrices que comportan estas normas propenden a la protección del niño, niña y adolescente que se encuentren en riesgo social, en las reglas se consignan sobre la rehabilitación y tratamiento del menor, al especificar la necesidad de subsanar los asuntos negativos que afectan al menor.

Estas reglas condicionan cinco principios para prevenir la comisión de delitos en menores: 1) prevención del delito en la sociedad, 2) creación de programas y servicios con base en la comunidad, 3) desarrollo armonioso de los niños, niñas y adolescentes, 4) cumplimiento de una función participativa en adolescentes en funciones sociales y 5) políticas de prevención de delincuencia juvenil. 
Tabla 1. El sistema de responsabilidad penal para adolescentes.

\begin{tabular}{|c|c|c|c|c|}
\hline PANAMÁ & CHILE & ECUADOR & PERÚ & COLOMBIA \\
\hline $\begin{array}{l}\text { Ley } 40 \text { de } \\
\text { agosto de } 1999\end{array}$ & $\begin{array}{l}\text { Ley de Respon- } \\
\text { sabilidad Penal } \\
\text { Ad ole sce nte } \\
\left(\mathrm{N}^{\circ} 20.084\right)\end{array}$ & $\begin{array}{l}\text { (CNA) Código } \\
\text { de la Niñez y la } \\
\text { Adolescencia } \\
\text { (Ley No. 2002- } \\
\text { 100) }\end{array}$ & $\begin{array}{l}\text { Código de Ni- } \\
\text { ños y Adoles- } \\
\text { centes }\end{array}$ & $\begin{array}{l}\text { Ley } 1098 \text { de } \\
2006\end{array}$ \\
\hline $\begin{array}{l}\text { El Régimen } \\
\text { Especial de } \\
\text { Responsabili- } \\
\text { dad Penal para } \\
\text { la Adolescen- } \\
\text { cia es aplicable } \\
\text { para menores } \\
\text { que hayan } \\
\text { cumplido } \\
\text { catorce años } \\
\text { en la comisión } \\
\text { de conductas } \\
\text { penales. Cuen- } \\
\text { ta con tres } \\
\text { finalidades: } \\
\text { 1. Educación } \\
\text { 2. Defensa de } \\
\text { la sociedad }\end{array}$ & $\begin{array}{l}\text { En la legisla- } \\
\text { ción chilena la } \\
\text { presente ley } \\
\text { es aplicable a } \\
\text { menores de } \\
\text { entre los } 14 \text { y } \\
18 \text { años. Los } \\
\text { jueces son la } \\
\text { máxima auto- } \\
\text { ridad encar- } \\
\text { gada de uno } \\
\text { de los pilares } \\
\text { fundamentales } \\
\text { que promue- } \\
\text { ven la Ley, } \\
\text { como lo es la } \\
\text { integración } \\
\text { social del jo- } \\
\text { ven con ayuda } \\
\text { de programas } \\
\text { especiales en } \\
\text { materia de } \\
\text { infancia y ado- } \\
\text { lescencia. }\end{array}$ & $\begin{array}{l}\text { El Sistema } \\
\text { Penal de Res- } \\
\text { ponsabilidad } \\
\text { del Adolescen- } \\
\text { te, es aplicable } \\
\text { para los meno- } \\
\text { res de entre } 12 \\
\text { y } 17 \text { años que } \\
\text { cometan un } \\
\text { hecho punible. } \\
\text { El fiscal del } \\
\text { Ministerio } \\
\text { Público, en } \\
\text { conjunto con } \\
\text { el Consejo de } \\
\text { Protección, } \\
\text { son los entes } \\
\text { encargados } \\
\text { de realizar la } \\
\text { detención del } \\
\text { menor y sus } \\
\text { garantías. }\end{array}$ & $\begin{array}{l}\text { El presente } \\
\text { código rige en } \\
\text { conexidad con } \\
\text { la doctrina de } \\
\text { Protección In- } \\
\text { tegral que con- } \\
\text { tiene una serie } \\
\text { de principios. } \\
\text { Con respec- } \\
\text { to a la parte } \\
\text { procesal, Perú } \\
\text { se enfatiza } \\
\text { explícitamente } \\
\text { en los proce- } \\
\text { sos judiciales } \\
\text { como uno de } \\
\text { los sistemas } \\
\text { especializados } \\
\text { de más vigi- } \\
\text { lancia. }\end{array}$ & $\begin{array}{l}\text { El Código de } \\
\text { la Infancia y } \\
\text { adolescencia } \\
\text { en Colombia } \\
\text { integra una se- } \\
\text { rie de normas } \\
\text { sustanciales y } \\
\text { procesales que } \\
\text { promueven } \\
\text { la protección } \\
\text { integral del } \\
\text { menor. No } \\
\text { obstante, el } \\
\text { reconoci- } \\
\text { miento de } \\
\text { sus derechos } \\
\text { y libertades } \\
\text { es abstracto. } \\
\text { Aplica para } \\
\text { mayores de } 14 \\
\text { años y meno- } \\
\text { res de } 18 \text { años. } \\
\text { Esta ley, a su } \\
\text { vez, reconoce } \\
\text { a los menores } \\
\text { como sujetos } \\
\text { de especial } \\
\text { protección } \\
\text { constitucional. }\end{array}$ \\
\hline
\end{tabular}

Fuente: Grupo editorial Ibáñez. 2012.

\section{JURISPRUDENCIA EN COLOMBIA}

Dando paso al enfoque cuantitativo, el mismo contiene información de Colombia, y utilizando la metodología de construcción de matriz para evidenciar las semejanzas y diferencias, así como para identificar los vacíos y medidas necesarias en la detención ilegal en menores. 
comprensión más clara del tema. Así mismo, la Tabla 2 esclarece los artículos en litigio y los derechos en defensa para identificar con qué rigor actúan el Estado ante la detención ilegal en menores.

En Colombia se trabajó una sentencia del Consejo de Estado en la Sala de lo Contencioso Administrativo relativo a la detención ilegal en menores de edad, que permite identificar qué disposiciones internacionales mencionan con reconocimiento a las fallas del servicio de la Administración de Justicia.

Los mandatos internacionales que en la Tabla 1 se mencionan, configuran un avance significativo de la implementación de los mandatos internacionales, comprendidos en cada País. Entre tanto, se cuenta con poca jurisprudencia que se ajuste a los lineamientos del presente trabajo de investigación. Por lo tanto, se hace oportuno realizar un análisis crítico de la teoría planteada con respecto a este fenómeno para edificar nuevos aportes para el Ordenamiento Jurídico Colombiano, en materia de menores en conflicto con la Ley penal.

La jurisprudencia colombiana no cuenta con un número significativo de precedentes con respecto a los menores infractores catalogados entre los 14 y 18 años, lo que permite entender que el Estado acciona con más severidad a la esperada por las garantías de menores y la protección de su integridad. Sin embargo, el tema no tiene tanta fuerza normativa; es por ello que es necesario plantear una serie de elementos para tener en cuenta, ya que se puede evidenciar que la carencia de aspectos jurisdiccionales implica un escaso marco legal para motivar al juez. Al inducir estas comprensiones, permite aducir la defensa de los derechos de la Convención Americana Sobre Derechos Humanos en su artículo. Pese al incumplimiento por parte de la Administración en sus actuaciones, el Estado colombiano reconoce los derechos:

1. Reconoce el Derecho a la Libertad y Seguridad Personal por medio de la responsabilidad objetiva, que obedece al reconocimiento patrimonial como resarcimiento de daños.

2. Se reconoce que la detención se realizó de forma arbitraria al pretender juzgarlo con la edad mayor a la que efectivamente tenía, pues, al momento de los hechos era menor de edad. No obstante, se reconoce que es víctima de la violencia por ser menor de edad y necesita protección del Estado

3. La dilación del proceso por falta de competencia demuestra la infracción del numeral 5 de la Convención Americana sobre Derechos Humanos. El Estado reconoce esta actuación.

4. Finalmente, se demuestra la vulneración del numeral 6 de la presente convención, pues la falta de competencia no es una excusa de la administración al evadir garantizarle el debido proceso y el derecho a la defensa del menor. 
Tabla 2. Precedente Jurisprudencial: Corte de Cierre Colombiana CONSEJO DE ESTADO

\section{COLOMBIA}

\begin{tabular}{|c|c|c|}
\hline $\begin{array}{l}\text { Identificación de la } \\
\text { providencia }\end{array}$ & $\begin{array}{l}\text { Consejo de Estado } \\
\text { Sala de lo Contencioso } \\
\text { Administrativo } \\
\text { Sección Tercera }\end{array}$ & $\begin{array}{l}\text { Radicación número: } \\
\text { 20001-23-31-000-2009- } \\
\text { 00296-01(42867) } 7 \text { de } \\
\text { Julio de } 2016\end{array}$ \\
\hline Actor & Efraín Chinchilla Uribe & Y otros \\
\hline Demandado & Nación - Rama Judicial & $\begin{array}{l}\text { Fiscalía General de la } \\
\text { Nación }\end{array}$ \\
\hline Referencia & Acción de reparación directa & $\begin{array}{l}\text { (Auto aprueba conciliación } \\
\text { judicial) }\end{array}$ \\
\hline $\begin{array}{l}\text { Aspecto Jurídico } \\
\text { Considerado }\end{array}$ & Privación Injusta de la Libertad & $\begin{array}{l}\text { En menor de edad } \\
\text { vinculado a la Guerrilla. }\end{array}$ \\
\hline \multirow{5}{*}{$\begin{array}{l}\text { Derechos vulnerados } \\
\text { reconocidos }\end{array}$} & $\begin{array}{l}\text { Privación injusta de la libertad por } \\
\text { falla en el servicio }\end{array}$ & $\begin{array}{l}\text { Daño antijurídico por } \\
\text { privación de libertad } \\
\text { personal }\end{array}$ \\
\hline & $\begin{array}{l}\text { Responsabilidad de la } \\
\text { administración de justicia: acceso } \\
\text { a la Justicia }\end{array}$ & $\begin{array}{l}\text { Artículo } 90 . \\
\text { Responsabilidad del } \\
\text { Estado patrimonialmente }\end{array}$ \\
\hline & & Detención Injusta \\
\hline & $\begin{array}{l}\text { Menores como sujetos de especial } \\
\text { protección constitucional. }\end{array}$ & $\begin{array}{l}\text { Artículo } 24 \text { Pacto } \\
\text { Internacional de Derechos } \\
\text { Civiles y Políticos. }\end{array}$ \\
\hline & Ley 74 de 1976. & $\begin{array}{l}\text { Artículo } 19 \text { de la } \\
\text { Convención Americana } \\
\text { sobre Derechos Humanos } \\
\text { ratificada por la Ley } 16 \text { de } \\
1972 .\end{array}$ \\
\hline \multirow{3}{*}{$\begin{array}{l}\text { Derechos reconocidos } \\
\text { en la providencia }\end{array}$} & $\begin{array}{l}\text { Convención Internacional de los } \\
\text { Derechos del Niño, aprobada por } \\
\text { la Ley } 12 \text { de } 1991 \text {, en el Protoco- } \\
\text { lo Adicional II a los Convenios de } \\
\text { Ginebra, ratificados por la Ley } 171 \\
\text { de } 1994 \text {. }\end{array}$ & $\begin{array}{l}\text { Artículo } 38 \text { del Protocolo } \\
\text { Facultativo de la Conven- } \\
\text { ción sobre los Derechos } \\
\text { del Niño, relativo a su par- } \\
\text { ticipación en los conflictos } \\
\text { armados, ratificado por la } \\
\text { Ley } 833 \text { de } 2003 \text {. }\end{array}$ \\
\hline & $\begin{array}{l}\text { El Estatuto de Roma, ratificado por } \\
\text { Colombia en la Ley } 742 \text { de } 2002 \text {, } \\
\text { define el reclutamiento de meno- } \\
\text { res como un crimen de guerra. }\end{array}$ & $\begin{array}{l}\text { El artículo } 162 \text { de la Ley } \\
599 \text { del } 2000 \text {, Código Pe- } \\
\text { nal Colombiano, tipifica el } \\
\text { reclutamiento de menores } \\
\text { de } 18 \text { años como un delito } \\
\text { que atenta contra las per- } \\
\text { sonas y bienes protegidos } \\
\text { por el Derecho Internacio- } \\
\text { nal Humanitario. }\end{array}$ \\
\hline & $\begin{array}{l}\text { Artículos } 37 \text { y } 40 \text { de la Convención } \\
\text { Internacional sobre los Derechos } \\
\text { del Niño y el artículo } 5 \text { de la Con- } \\
\text { vención Americana sobre Dere- } \\
\text { chos Humano. }\end{array}$ & $\begin{array}{l}\text { Artículo } 16 \text { y } 127 \text { del } \\
\text { Código de Infancia y Ado- } \\
\text { lescencia. }\end{array}$ \\
\hline
\end{tabular}




\section{APORTES PERSONALES}

1. El sistema de Responsabilidad Penal Adolescente debe reformular otras medidas de aseguramiento como las establecidas por el Código de Procedimiento Penal, teniendo en cuenta el especial tratamiento al menor, puesto que es importante contar con alternativas pedagógicas que fortalezcan la condición de formación y rehabilitación del menor.

2. Es indispensable que la formulación de las medidas de restricción de libertad sea en concordancia con los principios constitucionales, asegurando los bienes jurídicos de los niños, niñas y adolescentes.

Lo anterior no se acoge a solo una medida establecida como privación de la libertad del menor, pues resulta contrario a los propósitos y principios del SRPA; solo la restricción de la libertad del menor infractor conduce a la restricción de sus prerrogativas.

3. Es importante traer a colación algunos procedimientos de UNICEF que no implementan en el CIA como la creación de las instancias interinstitucionales con el fin de garantizar el principio de celeridad establecido en el Código General del Proceso en apoyo al Ministerio Público e Instituto Colombiano de Bienestar Familiar.

4. S oportuno generar una ley que promueva la protección integral de menores de edad con conflictos penal donde se especifiquen estándares rigurosos del internamiento o reclusión de los menores y unos términos perentorios de permanencia vigilada por organizaciones en la defensa de los derechos del menor, con la finalidad de evitar algún tipo de arbitrariedad e ilegalidad.

5. La creación de medidas restrictivas de libertad del menor permita, entre otras cosas, no conceder la libertad por falta de condiciones, como sucede en los Centros de Reclusión, sino que todo el proceso se adecúe a los fines pedagógicos para poseer acciones más efectivas con respecto de la jurisdicción del menor. En otras palabras, es necesario neutralizar el factor negativo de carencia de posibilidades de control de las conductas irregulares de los menores.

6. En cuanto a la detención del menor se debe garantizar la plena asistencia jurídica por un funcionario autorizado que realice los registros respectivos con notificación a los familiares para brindar el resguardo de los derechos integrales y especiales, además, que todas las etapas de detención garanticen un ambiente adecuado al menor 


\section{CONCLUSIONES}

Esta investigación tuvo como principal objetivo la indagación de la detención ilegal en Colombia. Como en la primera fase se verificó, los presupuestos procesales son necesarios al momento de una detención, y esto permitió establecer una contextualización más cercana desde la libertad personal y sus aspectos jurídicos, para llevar el tema a un plano más específico: el de los menores de edad como sujetos de especial protección constitucional.

En la época antigua se presenta este fenómeno a pesar de su poca regulación. La detención ilegal comenzó mucho antes del siglo XX, y es muy notoria la nueva concepción de los menores como sujetos de derechos que se debió implantar mucho antes, puesto que los menores son el pilar de la sociedad. Se evidencia, además, que entre los países cuya legislación fue comparada, la regulación es diferente en cuanto a la edad y discernimiento del menor. Sin embargo, todos propenden a la protección integral y a las garantías constitucionales.

Con respecto a los antecedentes, se evidencia que son pocos, así como su noción de detención ilegal. Resultó necesario indagar acerca de los principios, reglas y tratados a lo largo del tiempo en el ordenamiento interno. De esta manera se evidenciaron las directrices de los organismos internacionales al momento de realizar procedimientos a menores de edad. Contrario a esto, se configura ilegalidad, y las diferentes nociones de respaldo de Derechos Humanos en niños, niñas y adolescentes.

La corte de cierre del Consejo de Estado detenta solo un precedente jurisprudencial que reconoce a los menores como sujetos de especial protección constitucional y todos los derechos consagrados, no solo por la convención americana sobre derechos humanos, sino por otros pactos similares. Pese al escaso recurso jurisprudencial, se identifican plenamente las inclusiones de derechos en el panorama internacional, cosa que permite realizar nuevos aportes.

Los organismos internaciones desde el siglo XX realizaron un gran esfuerzo con los Estados Partes, puesto que influenciaron en el marco normativo interno. Gracias a esto, los principios rectores, en materia de responsabilidad penal para menores, estabilizan el ámbito procesal.

\section{REFERENCIAS BIBLIOGRÁFICAS}

Agencia Nacional de Defensa Jurídica del Estado. (2013) Privación injusta de la libertad: entre el derecho penal y el derecho administrativo. Giro-Graphos Ltda, Bogotá, Colombia. 
Blanco, C. (2006). Estudio histórico comparado de la legislación de menores infractores., T. II (s.f.). México: UNAM. Obtenido de: https://archivos.juridicas.unam.mx/www/bjv/libros/4/1968/7.pdf

Alemán, M. A. (2007) Reseña Histórica Sobre La Minoría De Edad Penal. Obtenido de: https://core.ac.uk/download/pdf/61894747.pdf

(1947) Jurisdiccion de menores. Ley 83 de 1946 (D.O: No. 26.363). Obtenido de: https://www.icbf.gov.co/cargues/avance/docs/ ley 0083 1946.htm

(1920) Ley 98 de 1920 (D.O: N. 17440 Y 17441). Obtenido de: $\quad$ http://www.suin-juriscol.gov.co/clp/contenidos.dll/ Leyes $/ 1837502$ ? fn $=$ document-frame.htm $\$ \mathrm{f}=$ templates $\$ 3.0$

(1968) Ley 75 de 1968, De La Filiacion, La Investigacion De La Paternidad Y Los Efectos Del Estado Civil. (D.O: No. 32.682). Obtenido de: https://www.icbf.gov.co/cargues/avance/docs/ley_0075 1968. $\underline{\mathrm{htm}}$

Congreso de la República de Colombia.(2006) Código Penal. Ley 906 del 2004. (D.O: 45.658). Obtenido de: http://www.secretariasenado. gov.co/senado/basedoc/ley_0906_2004.html

(2010) Por el cual se reglamenta parcialmente la Ley 1098 de 2006. [Decreto 860 de 2010] D.O: No. 47.653. Obtenido de: https:// www.icbf.gov.co/cargues/avance/docs/decreto 0860 2010.htm

(2010) LEY ESTATUTARIA 1622 DE 2013, por medio de la cual se expide el estatuto de ciudadanía juvenil y se dictan otras disposiciones. (D.O: No. 48.776). Obtenido de: https://www.icbf.gov.co/cargues/ avance/docs/ley 1622_2013.htm

(2006) Ley 1098 de 2006, por la cual se expide el Código de la Infancia y la Adolescencia. (D.O: No. 46.446) Obtenido de: https://www.icbf. gov.co/cargues/avance/docs/ley_1098_2006.htm

(2013) Ley Estatutaria 1622 de 2013, por medio de la cual se expide el estatuto de ciudadanía juvenil y se dictan otras disposiciones. (D.O: No. 48.776). Obtenido de:https://www.icbf.gov.co/cargues/ avance/docs/ley_1622 2013.htm

Consejo de Estado, Sala de lo Contencioso Administrativo. (2016) Sentencia 20001-23-31-000-2009-00296-01(42867) [M.P GUILLERMO SÁNCHEZ LUQUE]. Obtenido de: https://www. icbf.gov.co/cargues/avance/docs/20001-23-31-000-2009-00296$\underline{01(42867) \cdot \mathrm{htm}}$

Convención Americana sobre Derechos Humanos. (1969) Obtenido de: http://relapt.usta.edu.co/images/1969-Convencion-Americanasobre-Derechos-Humanos.pdf 
Corte Constitucional de Colombia, Sala Séptima de Revisión de Tutelas de la Corte Constitucional (2016) Sentencia T- 216. [M.P Jorge Ignacio Pretelt Chaljub] Obtenido de: http://www.corteconstitucional.gov. co/RELATORIA/2016/T-276-16.htm\# ftn19

Cruz y Cruz Elba. (2007) El concepto de menores infractores. Biblioteca jurídica virtual del Instituto de Investigaciones Jurídicas de la UNAM. Obtenido de: https://revistas-colaboracion.juridicas.unam.mx/ index.php/rev-posgrado-derecho/article/download/17168/15377

Díaz Cortés Lina M, (2009) Derecho penal de menores. Editorial Temis S.A, Bogotá, Colombia.

Comisión Interamericana de Derechos Humanos (CIDH). (2008). Principios y Buenas Prácticas sobre la Protección de las Personas Privadas de Libertad en las Américas. Whashington, D.C: OEA

Duran Leiva Pablo A. (2010) Curso de leyes especiales para alumnos de la escuela de formación de policía de carabineros Alguacil Mayor Juan de Almagro y los grupos de formación de carabineros de Chile. Universidad de Chile, Santiago de Chile.

Garzón Diazgranados Tulia E. (2000) Privación de la libertad y responsabilidad del estado. Pontificia Universidad Javeriana, Bogotá, Colombia.

Instituto Colombiano de Bienestar Familiar (ICBF). (2015). Adolescentes, Jóvenes Y Delitos. "Elementos para la comprensión de la delincuencia juvenil en Colombia". Colombia, Procesos Digitales S.A.S. Obtenido de: https://repository.oim.org.co/bitstream/ handle/20.500.11788/1647/95.\%20Boletin\%20ICBF\%20 Delincuencia\%20Juvenil.pdf? sequence $=1$ \&isAllowed $=y$

Loyola. S. y Muñoz. M. (2016) Vulneración de los Derechos Humanos en el arresto policial. Obtenido de: http://www.pensamientopenal.com. ar/system/files/2016/11/doctrina44432.pdf

Moya Vargas Manuel F. y Bernal Castro Carlos A. (2015) Los menores en el sistema penal colombiano. 1a ed. Universidad Católica de Colombia, Bogotá, Colombia.

Organización de las Naciones Unidas (ONU)

(1959) Declaración de los Derechos del Niño. Obtenido de: https:// www.humanium.org/es/declaracion-1959/

(1990A). Directrices de las Naciones Unidas para la prevención de la delincuencia juvenil (Directrices de Riad) Obtenido de:https://www.ohchr.org/sp/professionalinterest/pages/ preventionofjuveniledelinquency.aspx 
(1990B) Reglas De Las Naciones Unidas Para La Protección De Los Menores Privados De Libertad. Obtenido de: http://relapt.usta. edu.co/images/1990-Reglas-de-las-NNUU-para-la-Proteccion-delos-Menores-Privados-de-Libertad.pdf

(2018) La Declaración Universal de Derechos Humanos. Obtenido de: http://www.un.org/es/universal-declaration-human-rights/

(1966) Pacto Internacional de Derechos Civiles y Políticos. (1966) Recuperado el 11 de octubre de 2018 de: https://www.ohchr.org/ sp/professionalinterest/pages/ccpr.aspx

Prato R. Luisa Jackeline. (2016) La responsabilidad del estado por la privación injusta de la libertad en Colombia. Universidad Colegio Mayor De Nuestra Señora Del Rosario Bogotá, Colombia.

Serrano Escobar Luis G. y Tejada Ruiz Claudia P. (2014) La responsabilidad patrimonial del estado. Ediciones Doctrina y Ley Ltda, Bogotá, Colombia.

UNICEF. (s.f) Niños en conflicto con la ley. Obtenido de: https://www. unicef.org/spanish/protection/files/FactSheet_conflict_with law_sp.pdf

Useche Bohórquez Carolina. (2012) El sistema de responsabilidad penal para adolescentes. Grupo editorial Ibáñez, Bogotá, Colombia. 